\title{
Herramientas de la economía del bien común para la transformación económica, social y política
}

\author{
Verónica Gómez Calvo \\ USAC-Universidad de Nevada, Reno (EEUU) \\ Rosario Gómez-Álvarez Díaz \\ Universidad de Sevilla (España)
}

Sumario: 1. Introducción 2. Consecuencias de la Economía de Mercado. 3. Valores y Economía, ¿han estado alguna vez unidas? 3.1. Perspectiva histórica. 3.2. Valores de la Economía Social, la Economía Solidaria y la Economía del Bien Común. 4. La democracia como vía y fin de la Economía con Valores. 4.1. La Teoría del Constitucionalismo Democrático. 5. El proceso de transformación de la EBC. 6. Conclusión. Bibliografía.

Resumen: Este artículo pretende mostrar las aportaciones teóricas y prácticas de la EBC, a través de la incorporación de los valores de la Economía Social al funcionamiento del sistema económico y la profundización de la democracia como herramientas indispensables para la construcción de un nuevo modelo económico, que tenga como objetivo transformar la realidad económica, social y política, servir al interés de la sociedad en su conjunto y al desarrollo humano, analizando cómo podemos reconducir la economía y la sociedad hacía un modelo más justo mediante la puesta en marcha de un cambio de paradigma en nuestras actividades económicas.

Palabras clave: bien común, economía social, solidaria, democracia, valores.

Abstract: This article aims to show how the contributions of the ECG, the incorporation of the values of the Social economy to the functioning of the economic system and the deepening of democracy are indispensable tools for the construction of a new economic model, which aimed to transform the economic, social and political reality, serve the interest of the society as a whole and the human development, analyzing how we can redirect the economy and society towards a more just model through the implementation of a paradigm shift in our economic activities.

Key words: solidarity economy, economy for the common good, social economy, democracy, values. 


\section{Introducción}

Este artículo pretende mostrar las aportaciones teóricas y prácticas de la EBC, a través de la incorporación de los valores de la Economía Social al funcionamiento del sistema económico y de la profundización de la democracia como herramientas indispensables para la construcción de un nuevo modelo económico, que sirva para transformar la realidad económica, social y política, a los intereses de la sociedad en su conjunto y al desarrollo humano. Analizaremos las alternativas que propone la Economía del Bien Común frente a la pérdida de los valores sociales que se ha promovido durante las últimas décadas a través del actual modelo económico neoliberal basado en la maximización del beneficio individual, y la recesión de los valores comunes a la sociedad como la cooperación, la solidaridad, la confianza y la justicia social que caracterizan al ser humano, y cómo podemos reconducir la economía y la sociedad hacía un modelo más justo mediante la puesta en marcha de un cambio de paradigma en nuestras actividades económicas, la integración de ciertos valores, que no deben tener como objetivo final el afán de lucro sino generar un impacto positivo al entorno contribuyendo al bien común de nuestras sociedades y el entorno natural, el respaldo a la participación ciudadana y la profundización de la democracia representativa hacia una democracia también participativa y directa.

\section{Consecuencias de la economía de mercado}

¿Qué entendemos por mercado? La definición más sencilla es la de un lugar donde la gente compra y vende bienes y servicios. Sin embargo, cuando hablamos de mercados no nos referimos a un lugar, sino al conjunto de disposiciones que posibilitan el intercambio, independientemente de dónde se dé el mismo.

Por ejemplo, el mercado de trigo hace referencia a un sistema de relaciones entre agricultores, comerciantes, molineros, vendedores y distintos usuarios de harina; si hablamos del mercado de valores, no nos referimos sólo a Wall Street, sino al conjunto de disposiciones que incluye leyes, convenciones, infraestructura física y social, y la distribución de riqueza y la propiedad, sobre cuya base se realizan los intercambios.

Es particularmente importante el derecho de propiedad, pues para poder intercambiar algo es necesario saber lo que significa la propiedad, de qué se puede ser propietario y cómo se puede disponer de 
ello. Por ejemplo, los mercados de formas de vida eran inexistentes hasta hace relativamente poco tiempo, pues antes no era posible ser propietario de una forma de vida, como es el caso de las variedades de semillas.

Este conjunto de disposiciones sobre las que se realizan los intercambios incluye también la infraestructura física y social: las carreteras y medios de transporte, las telecomunicaciones y médicos de comunicación, el conocimiento sobre la producción y los precios, por ejemplo. Otro efecto importante que opera en el mercado es el poder de comprar, cuando hay mucha oferta (por ej., médicos) y las posibilidades de compra son equitativas, el mercado no funciona igual que cuando ésta es escasa y la capacidad de compra es muy desigual. Por tanto, la determinación de los salarios y la distribución de la riqueza de un país está determinado, en gran parte, por el funcionamiento del mercado, y a su vez ésta distribución afecta a los resultados del mercado.

Teniendo en cuenta todos estos aspectos que influyen en las características concretas de los mercados, no nos queda otro remedio que reconocer el papel fundamental del Estado en la constitución de los mismos, dada su importancia para determinar los derechos de propiedad, de establecer una infraestructura física y social determinada, y de afectar a la distribución del ingreso y la riqueza. Es por ello muy engañoso cuando se discute de política económica y se presentan los argumentos como: «Estado contra mercado», el mercado no es una alternativa al Estado, sino que existen y se definen con características concretas gracias precisamente a la intervención del Estado (MacEwan, A. 2001:189).

Los mercados no son «naturales», por el contrario, son un conjunto de relaciones sociales y reglas establecidas que determinan las condiciones en las que se realizan los intercambios comerciales. Por tanto, son consecuencia del ejercicio de poder del Estado, o de otras instancias supraestatales, por las cuales dichos mercados son instituidos; ni son «neutrales», pues deciden qué intercambios son posibles y cuáles no, y en qué términos, favoreciendo a unos grupos en lugar de otros. Las reglas del juego, las que dictan cómo deben operar los mercados, se deciden antes de los mercados empiecen a operar, determinando que intercambios son autorizados y qué intereses son beneficiados.

El mercado lo que refleja es en realidad una estructura determinada de relaciones de poder, en las cuales, las agencias estatales asumen la función de hacer cumplir los acuerdos y de ejercer como árbitro en disputas, siendo en todo momento, garantes del adecuado funcionamiento de unos mercados que ya han sido instituidos previamente 
en relación a los intereses de ciertos grupos con poder (MacEwan, A. 2001:178).

Desde la perspectiva de la teoría económica la motivación de las acciones en el ámbito económico es el egoísmo, o propio interés, y por ello las personas buscan obtener de cada intercambio que realizan el máximo beneficio posible. En el caso de los oferentes tratará de producir los mejores bienes y de hacerlo lo más barato posible, pues ha de competir con muchos otros productores/vendedores. Si un producto es demandado, su precio subirá, y esta información, que es obtenida de forma instantánea por todos los participantes en el mercado, es indicativa para el empresariado de que existe una oportunidad de negocio. También de forma instantánea, las empresas imitadoras copiarán el producto, y el aumento de la oferta permitirá satisfacer esa demanda. Como todos harán lo mismo, obtendremos que, por un lado, todos los recursos disponibles habrían sido empleados óptimamente y el conjunto de bienes existentes aumentarán hasta su máximo posible; y, por otro, esos bienes se distribuirán de acuerdo con la contribución de cada uno al proceso productivo.

Como es bien sabido, este resultado que predice Adam Smith se fundamenta en el supuesto teórico de que existe una «mano invisible» es decir que los mercados funcionan bajo competencia perfecta.

Evidentemente en el mundo real no se cumplen estos supuestos, por lo que los resultados esperados del comportamiento egoísta de las empresas dista mucho de lograr el beneficio para la sociedad, muy al contrario, el mercado logra el beneficio de unos pocos a costa del resto de personas. De hecho, las predicciones teóricas de los modelos de la teoría económica de los mercados sin competencia perfecta predicen y explican los resultados reales. En concreto, el empresario que sobrevive en el mercado es aquel que ofrece un buen producto más barato que los competidores, luego tiene incentivos para minimizar sus costes monetarios, y por tanto para trasladar los costes de los demás, es decir para crear externalidades negativas, de forma que el bien personal entra en conflicto con el bien para los demás. Asimismo, las empresas tienen incentivos para crear barreras de entrada, gracias a la acumulación de beneficios que se convierte en medio y fin de la actividad productiva, para evitar que otras empresas participen en el mercado, y como resultado habrá menos producción, a precios más elevados (monopolio u oligopolio).

Si además evaluamos los resultados en términos de lo que se produce, el mercado capitalista no produce aquello que permite a las personas garantizar una vida digna, sino en producir lo que demanden las personas que tiene renta, son las que tienen derecho al voto econó- 
mico (Sampedro, 2002): «Y puesto que en el mercado el dinero es el que da la «libertad de elegir» resulta que en el mercado llamado «libre» los poderosos efectivamente eligen mientras que los débiles se resignan con lo inferior o con nada». Por ello es compatible que en una sociedad cuyo sistema económico se basa en el mercado capitalista se produzca productos de lujo, a la vez que una parte de la población no tiene acceso a bienes básicos.

Respecto al reparto de los recursos, todas las personas que no intervienen en un proceso productivo de mercado no reciben ningún tipo de recurso o pago, por lo que, estas personas están abocadas a la total inanición, pues no existe ningún mecanismo del propio sistema para evitar estas situaciones. En cuanto a las personas que participan en el proceso productivo son retribuidas según el valor de su productividad marginal, siempre que exista competencia perfecta. Esto supone que a las personas se les paga en función del precio del producto que están generando y de su productividad marginal como factor. Dicha productividad, a su vez depende de su cualificación y dotes personales, así como de la cantidad total de factor contratado y del resto de factores empleados en el proceso productivo y su organización. Es evidente, por tanto, que el valor de la aportación de cada persona no depende sólo de su propio esfuerzo individual, sino también del de los demás, y de toda una serie de componentes organizacionales. Ahora bien, este criterio de reparto no garantiza que las personas obtengan una participación en el reparto de la renta que les posibilite tener medios materiales para una vida digna. Pero además, como la competencia perfecta, sencillamente no existe porque la información no es completa, ni tampoco existe perfecta movilidad, las retribuciones se fijan dentro de un juego de negociación donde existe asimetría en la capacidad de negociación, y donde el propietario del capital puede, y de hecho lo hace, imponer sus condiciones de retribución, ejerciendo el poder de monopsonio. El resultado es conocido por todos, pues en países con niveles del PIB elevados existe una parte importante de la población bajo el umbral de la pobreza, aun encontrándose empleadas, y con grandes desigualdades en la distribución de la renta y de la riqueza. De hecho, la pobreza, no es un estado natural, sino un estado social derivado de un marco jurídico e institucional concreto.

Además, los mecanismos de ajuste entre la oferta y la demanda exigen desplazamientos de los factores hacia nuevas actividades, pero las personas no tienen la posibilidad de adaptarse a cualquier empleo, debido a la diferencia de destrezas, capacitación, etc. Eso supone que los periodos de adaptación de las personas, ya sea como trabajadores o en su actividad empresarial, a nuevos sectores requieren un tiempo, 
que en algunos casos puede ser muy largo, pues como bien decía Keynes (1923:47): "a largo plazo, todos muertos», por tanto pueden pasar años hasta que la economía se haya ajustado, lo que puede llevar a gran parte de la población a un estado de desempleo y de pobreza.

Por añadidura, la maximización de beneficios y su apropiación por el empresariado, actualmente accionistas y directivos, es la consecuencia simple de una teoría de los derechos de propiedad que diseña el estado, y que predomina en la mayoría de los las legislaciones, y que legitima a que los accionistas sean los propietarios de todo el valor creado en la empresa, a partir de un trabajo colectivo, independientemente de su esfuerzo o del riesgo asumido.

En este proceso, se incumple el objetivo central de la economía que es satisfacer las necesidades de la personas, pues como clientes, proveedores y trabajadores, pasan a ser medios para maximizar el beneficio que obtiene el capital, sin importar los costes que éstos tengan que soportar. En definitiva, los resultados del mercado ya están descritos en la propia teoría económica clásica, lo más interesante es que se haya defendido sus bondades en función de la competencia perfecta, cuando todos los economistas saben que ésta no existe.

En la actualidad además, podemos hablar no sólo de mercados, sino de sistemas de mercados. No son la misma cosa, en las sociedades tradicionales existían mercados, pero estos eran secundarios, ya que en una familia campesina autosuficiente, podía producir para sus propias necesidades y sólo comerciaba para conseguir aquello que no podía producir por sí mima. En los sistemas de mercados, los mercados no sólo existen sino que se convierten en realidad en el factor principal de todos los asuntos económicos; pero todavía más importante, una sociedad que se desarrolla en un sistema de mercado se gestiona como un complemento del sistema de mercado mismo. "En lugar de que la economía se encaje en las relaciones sociales, éstas se encajan en el sistema económico» (Polanyi 1944:57). Supeditando de esta manera a todo el conjunto de la sociedad, incluyendo la política, al funcionamiento del sistema de mercado. Es lo que podríamos llamar hoy en día: la dictadura de los mercados, a la cual se subordina incluso el bienestar general de la ciudadanía.

El neoliberalismo equipara además al mercado con lo «racional» y cree que es el único modo de organización económica posible, aunque queden todavía muchas otras alternativas de organizar la vida económica, y aunque no sean sino el producto de unos factores institucionales (relaciones de poder, normas promulgadas, tradiciones, etc.) en una determinada etapa de evolución histórica del capitalismo (Esparta Soloeta, I 2002:13). 
Por esta razón, en lugar de la supremacía del mercado sobre cualquier otro ámbito, distintas corrientes, desde el institucionalismo económico, la teoría del constitucionalismo democrático, la economía solidaria, etc. así como la Economía del Bien Común, se aboga por una supeditación en todos los órdenes de la racionalidad de mercado a la racionalidad política democrática, es decir, a la voluntad social, como única manera de reequilibrar las relaciones de poder y hacer que el sistema económico funcione al servicio del bien común y del interés general.

El desarrollo democrático, desde esta perspectiva, se plantea como el recurso necesario para avanzar en mejoras de carácter instrumental que contribuyan en beneficio de toda la sociedad, para lo cual se reclama la participación ciudadana y la democracia participativa y directa, lo que implica que los afectados por la decisiones políticas tengan, no sólo voto, sino también voz en la toma de decisiones, de manera que la sociedad se conciba como una sociedad organizada a favor de la mayoría, y no de una minoría de poderosos, y se sitúe la política y el bienestar ciudadano por encima de la economía.

La democracia vive en la actualidad un período de crisis de legitimidad fruto de la desconfianza que generan las instituciones públicas y del dominio que ejercen las grandes corporaciones económicas sobre éstas. Este proceso de desafección de la ciudadanía hacia la capacidad del sistema democrático de garantizar unos derechos básicos sociales y políticos es en gran medida consecuencia de las políticas neoliberales que se han venido llevando a cabo desde los años 80 , y que han tenido su mayor incidencia a partir del empequeñecimiento del Estado y la reducción de su intervención.

El neoliberalismo se ha convertido en la herramienta perfecta para que las élites económicas mundiales mantengan, e incluso incrementen, su status quo, enriqueciéndose cada día más a costa de la pérdida de bienestar de las clases medias y trabajadoras. Las políticas neoliberales se han caracterizado por intentar reducir al mínimo el papel del Estado en la toma de decisiones económicas, justificando que la intervención estatal perjudica el curso de la economía y que el motor de esta es la competencia y el libre mercado y para ello, una de las estrategias centrales del neoliberalismo ha consistido en colocar sus principios fundamentales fuera del alcance de los mecanismos representativos.

De momento, podemos afirmar que el mayor éxito del neoliberalismo ha sido generalizar la creencia que en el actual contexto de globalización las únicas políticas económicas viables son las neoliberales, como así demuestra el hecho de que gobiernos liberales se vieran obligados a aplicar medidas de carácter marcadamente neoliberal basadas 
en la austeridad y el trasvase de dinero público a bancos en riesgo de quiebra tras el estallido de la crisis financiera de 2007.

Las grandes corporaciones han sido la herramienta idónea para extender la globalización económica neoliberal, así como los organismos económicos internacionales que toman decisiones de carácter global frente a los Estados, que como organismos individuales, no tienen igual capacidad de reacción y maniobra. Por otro lado, aunque en los Estados democráticos sus ciudadanos puedan ejercer el derecho a voto en diferentes elecciones y cuenten con otros mecanismos de representación y/o decisión (referéndums, iniciativas legislativas populares, etc.) cada vez más se ve relegada su participación política a favor de las decisiones de organismos estatales o supraestatales de las cuales se hallan excluidos. Los gobiernos elegidos democráticamente se han convertido, en el contexto de la globalización neoliberal, en simples agentes que se ven obligados a cumplir con las directrices económicas que provienen de las grandes corporaciones económicas y que promueven las mayores organizaciones internacionales, convirtiéndose así en meros instrumentos para llevar a cabo su objetivos, relegando totalmente, a su vez, a la ciudadanía a un plano secundario.

De esta manera, la democracia representativa, que fue antaño un mecanismo para conseguir mejoras de bienestar y la consagración de los derechos sociales y políticos, se ha convertido hoy en día en sombra de lo que era. De hecho, los ciudadanos han sufrido un claro retroceso en derechos políticos y sociales promovido a través de la no injerencia del estado en la economía y la continua privatización de los servicios públicos de carácter social.

En consecuencia, los ciudadanos se sienten impotentes ante la crisis y las decisiones que se toman en su nombre, la distancia entre éstos y sus representantes causada por la captura del poder político llevada a cabo por las élites económicas mundiales ha desembocado en la desafección política, la falta de confianza en las instituciones y la clase política, e incluso, el cuestionamiento y legitimidad de las decisiones adoptadas y el futuro del país.

\section{Valores y economía, ¿han estado alguna vez unidos?}

\subsection{Perspectiva histórica}

Desde orígenes antiguos, la economía ha tenido algún lazo de unión con la ética, la moral o la religión, como así demuestran los ejemplos de Aristóteles o Adam Smith para los dos primeros casos; 
el distanciamiento progresivo entre ética y economía se produce sobre todo gracias a la Economía Neoclásica y los procesos de modernización. Según avanzó el proceso de «racionalización moderna», y fue predominando el lado positivista y técnico de la economía, ésta se distanciaba de la ética, transformándose, aunque no para todos, en una ciencia y un modelo de «racionalidad económica» que excluía la ética, constituyendo de esta manera, un problema social.

Volviendo a los clásicos, Aristóteles consideraba a la Economía como parte del conjunto de las actividades humanas, vinculada como lo estaba tradicionalmente, con la buena administración de los bienes. En este contexto clásico antiguo, los valores éticos son constitutivos de la actividad económica porque es a través de ésta cuando se pone en práctica «la recta razón en dirección al bien del individuo y de la ciudad, conforme a un orden natural y comunitario» (Conil Sancho, J. 2006:81).

Desde esta óptica, la economía debe regirse por la razón y la naturaleza al servicio del bien de la comunidad. Por ello, la economía debe atenerse al orden social y natural de la ética y la política. De hecho, Aristóteles separaba la economía (el arte de lo productivo) de la crematística (la mera adquisición de riqueza y recursos), distinguiendo además en esta última entre la que procura recursos necesarios para vivir bien y es limitada, de la otra, en la que no hay límites y por la misma razón, va contra el orden natural.

Aristóteles consideraba además que la casa y la ciudad se constituían para la satisfacción de las necesidades humanas y para el buen vivir, ya que toda comunidad se constituye en vista a algún bien y el hombre es animal político y con logos, es decir, necesariamente distingue entre lo que es conveniente y lo que es dañino, lo que es justo y lo que es injusto, entre el bien y el mal, y así como el hombre no se basta para vivir sólo, vive en comunidad porque así lo ha dispuesto la naturaleza; y esto incluye el sentido de la justicia en cada ámbito, ya que la justicia es el orden de la comunidad política. Por las mismas razones, y aunque es cierto que una aplicación directa de la teoría económica de Aristóteles hoy en día sería imposible dados los cambios de la realidad histórica, la tradición aristotélica renueva la necesidad de volver al sentido clásico de la Economía Política, cuyo paradigma original enmarca la economía dentro de la filosofía práctica, políticomoral.

Por su lado, Adam Smith era profesor de Filosofía Moral y publicó en 1776 el libro que se considera fundacional de la Economía Moderna: «Investigación sobre la naturaleza y causas de la riqueza de las naciones». Para sorpresa quizás de algunos tras todas las ter- 
giversaciones que se han hecho sobre «la mano invisible» de Adam Smith, éste anclaba la Economía Política en una ética de carácter moderno. Si bien creía que el comportamiento económico se regía por el «egoísmo» —así no es en virtud de la humanidad o de la justicia por parte de los ricos, sino por una «mano invisible» o por una «providencia» que mueve y ordena los esfuerzos dispersos de los individuos en su propio provecho que se produce una distribución necesaria de los bienes - consideraba igualmente importante establecer instancias de control, como la justicia, ya que el interés propio puede llevar a que no se respeten los límites, y por ello debía mantenerse una actitud crítica y de descernimiento en el ámbito económico, siendo conscientes de las limitaciones del mercado. A Adam Smith le preocupaba que la búsqueda de ganancias privadas provocaran pérdidas sociales y por ello, era consciente de que el interés propio necesita de un control en el orden social, de manera que se protegiera el «sistema de libertad» en la sociedad comercial (Conill Sancho, J. 2006:107).

Para Smith, la economía está al servicio del bienestar dentro de un contexto de justicia social, porque en último término, de lo que se trata es de la realización de los individuos en libertad. Pero la ley y la responsabilidad social preceden al mercado, de manera que la economía sólo tiene sentido dentro de un contexto político, social e institucional con trasfondo moral. Su concepción económica se presenta, al igual que ocurre con Aristóteles, como Economía Política, ya que la economía es una herramienta poderosa para el desarrollo de los individuos y su finalidad es aumentar su libertad y bienestar.

En la actualidad, se oyen cada vez más voces de economistas que reconocen como la avaricia, el afán de lucro desmedido y la falta de auténticas guías (valores) nos han llevado por el camino erróneo, tomando las decisiones equivocadas, propagando la corrupción, y después volviendo a tomar más decisiones equivocadas en una huida hacia adelante para no reconocer los propios errores y perpetuar el mismo estado de cosas. Esto les ha llevado a plantearse la necesidad de incorporar la dimensión ética a la economía y regirse por otros valores. Pero no sólo en la economía es dónde son necesarios.

Adela Cortina, en su libro «¿Para qué sirve realmente la ética?», desgrana toda una serie de argumentaciones para hacernos conscientes de que los valores morales, éticos, son las únicas guías capaces de hacer del hombre, un hombre feliz, ya no digamos para vivir felices en sociedad. A nivel personal, cuanto más éticos seamos, más acertadas serán nuestras decisiones y más cerca estaremos de ser personas felices y completas. Al menos así lo creían los filósofos griegos, que el 
bien obrar lleva a la felicidad porque la felicidad consiste en obrar bien y tener buena suerte. Pero como dice Adela Cortina, trabajar para la justicia es incómodo, exige afrontar situaciones desagradables, desde situaciones sencillas que se dan en nuestra vida cotidiana hasta las situaciones que van contracorriente en un mundo desigual e insolidario. Por eso, afirma, cuesta tanto conjugar la justicia y la felicidad, porque la felicidad pocas veces es entendida como autorrealización, acompañada de cierta suerte, sino simplemente como «estar bien», "y como se dice en mi tierra, ..., el que esté bien, que no se mueva» (Cortina, $\mathrm{A}$. 2013:169)

Es decir, ser justos muchas veces no es la opción más fácil y cómoda, pero el camino a la autorrealización y el desarrollo personal no es nunca la opción fácil, ni la cómoda, siempre implica tener que enfrentarse a lo nuevo, a lo desconocido, y a lo incómodo, se puede ser inmovilista, no buscar ningún tipo de cambio para mantenernos en nuestra zona de «comodidad» que nada perturba, pero esta opción es estática y tarde o temprano estaremos en una jaula, y no de oro precisamente, sino de aburrimiento y frustración que no nos conducirá a ninguna parte. Esto vale también para la sociedad, cuanto más felices y más completos seamos, más podremos aportar a la sociedad y contribuir al beneficio de todos.

Debemos preguntarnos si nuestras necesidades se cumplen simplemente adquiriendo productos y acumulando riqueza, si el éxito y la felicidad sólo se miden por lo abultado de nuestra cuenta bancaria, o si cumplidas con ciertas necesidades de satisfacción material, el camino hacia la felicidad y la autorrealización, es otro.

\subsection{Valores de la Economía Social, la Economía Solidaria y la Economía del Bien Común}

El origen de las ideas y de las prácticas de cooperación están presentes en todas las épocas y las civilizaciones, pero en el entorno europeo surgen ante las necesidades de las personas más vulnerables e indefensas, que mediante la autoayuda buscan soluciones a sus problemas generados en el contexto del desarrollo industrial de los siglos XVIII y XIX (López Castellano, 2003:201).

La defensa explícita de los valores asociativos en la economía aparecen en las ideas de los denominados asociacionistas en el S. XVII, que serán defendidas por Sismonde 1819), con una mayor base humanística y teórica, planteando la necesidad de que la economía debía preocuparse por el bienestar de las personas y no por el volumen de produc- 
ción, y donde la cooperación es la herramienta para esa nueva economía. Posteriormente, Saint-Simon (1823) y sus seguidores promulgan las ideas estatalistas, donde desparece la propiedad privada, la herencia y la libre empresa, que son sustituídas por un estado, donde los medios de producción son colectivos y autogestionados.

En el siglo XIX, Owen, Fourier, King y Buchez, teorizan la idea de que la cooperación es el motor de cambio social mediante su aplicación al ámbito de la producción y el consumo, en un contexto de propiedad privada. Veían en el cooperativismo el medio de unión de los trabajadores para superar a los grandes capitalistas, así como en el consumerismo, las cooperativas de consumo, la base para la intersolidaridad entre las personas, donde el excedente tendría un destino económico, como era la reinversión en las cooperativas y social, fundamentalmente educativo y asistencial. Dicho proceso de cambio se fundamentaba en la confianza en los valores como mecanismo de transformación social, lo que llevó a los defensores del socialismo estatal a denominarlos «socialismo utópico».

Desde una perspectiva práctica, el movimiento cooperativo se inicia de la mano de «los Pioneros de Rochdale» en 1844 que se dotaron de una serie de normas, consideradas el origen de los principios cooperativistas y que se concretan en: voluntariedad, gestión democrática, interés limitado al capital, participación en excedentes, fomento educativo-asistencial y solidaridad intercooperativa y social. Ya en la segunda mitad del siglo XIX se produce el reconocimiento del cooperativismo en el derecho societario, se abre así una tercera vía jurídica entre la empresa capitalista y la empresa pública, se consolidan diferentes formas mutualistas y aparecen las primeras cooperativas de crédito.

De forma paralela, en el siglo xIX se consolida una segunda tendencia sobre el método para la transformación del sistema capitalista mediante la intervención pública. Por un lado, las propuestas marxistas proponen un modelo cooperativo fundamentado en la propiedad pública y la intervención estatal. Por otro, la idea de que el mercado es la mejor solución social para los problemas económicos es cuestionada por el último autor clásico, John Stuart Mill (1848), para el que las leyes de la distribución son casi por entero materia de la voluntad de cada uno y de las instituciones humanas, las cuales, a su vez, son producto de valores, costumbres, filosofías sociales y gustos cambiantes, y su mejora y su diseño corresponde al Estado. Sin embargo, su propuesta no es la propiedad pública, sino es un sector público que corrija la distribución injusta de la renta, y la libertad individual y social, donde esta se traduce en cooperación voluntaria en proyectos sociales y empresariales (Rosen, F., 2011:37). 
A partir de este autor surgirán todos los estudios sobre los «fallos del mercado», que será la línea argumentativa para la creación del Estado de bienestar, y que sustentará el crecimiento en Europa occidental durante el período 1945-1975 caracterizado principalmente por el sector capitalista privado tradicional y el sector público. Ya en el siglo XX, como bien destaca Divar (2012, p. 49), las ideas cooperativistas se centran en la gestión empresarial, pasando a un segundo plano el papel de motor de cambio social.

Sin embargo, debido a la crisis de dicho Estado de Bienestar, junto a las crisis económicas, la economía de mercado no soluciona los problemas como el desempleo masivo, la exclusión social, el bienestar en zonas degradadas, la salud, la educación, la calidad de vida de los pensionistas o el desarrollo sostenible. En ese contexto, en 1980 se publica la Carta de la economía social que la define como el conjunto de organizaciones que no pertenecen al sector público, funcionan de manera democrática con igualdad de derechos y obligaciones de los socios, y practican un régimen particular de propiedad y distribución de los beneficios, empleando los excedentes para ampliar la entidad y mejorar los servicios prestados a sus socios y a la sociedad (Monzón, 2011:35). Bajo el paraguas de la Economía Social se engloban las cooperativas y las mutuas y las entidades de no mercado como son las asociaciones y fundaciones. Todas ellas comparten una serie de principios, que recogen la tradición cooperativista, y que fueron aprobadas por sus propias entidades en "La Carta de principios de la economía social» y que son: primacía de la persona y del objetivo social por encima del capital; adhesión voluntaria y abierta; control democrático ejercido por sus miembros combinación de los intereses de los miembros usuarios y/o del interés general; defensa y aplicación de los principios de solidaridad y responsabilidad; autonomía de gestión e independencia respecto de los poderes públicos; utilización de la mayoría de los excedentes para la consecución de objetivos a favor del desarrollo sostenible, los servicios de interés para los miembros y el interés general. ${ }^{1}$

Posteriormente, aparece el enfoque de la economía solidaria, que se desarrolló en Francia y en algunos países latinoamericanos durante el último cuarto del siglo xx, y se asocia en gran medida al importante crecimiento que el tercer sector ha experimentado en número de organizaciones que producen y distribuyen algunos de denominados bie-

1 Déclaration finale commune des organisations européennes de l'Économie Sociale, CEP-CMAF, 20 de junio de 2002. 
nes sociales o preferentes para sectores de población que difícilmente pueden incorporarse a la economía de mercado, como es el caso de los discapacitados, personas maltratadas, inmigrantes, etc. Es en estos ámbitos donde algunas organizaciones como las cooperativas y, sobre todo, asociaciones han experimentado una notable expansión. Este sector agrupa simultáneamente a un conjunto de nuevas organizaciones y nuevos ámbitos de actuación. En comparación con los agentes clásicos de la economía social presenta tres características distintivas: a) las demandas sociales que intenta atender, b) los actores que están detrás de estas iniciativas y c) el deseo explícito de un cambio social y no sólo de gestión empresarial.

Sobre la base de estos tres aspectos se desarrolló el concepto de economía solidaria en Francia a partir de 1980, que incorpora el principio de reciprocidad en la actividad económica, mediante las aportaciones del voluntariado. ${ }^{2}$ A diferencia del enfoque europeo, que considera que la economía solidaria es compatible con el mercado y el estado, la perspectiva latinoamericana se centra en el desarrollo de este concepto como alternativa mundial al capitalismo. (Luis Razeto,1984)

Así la economía solidaria, es un enfoque de la actividad económica que tiene en cuenta a las personas, el medio ambiente y el desarroIlo sostenible y sustentable. Por ello, es una manera de vivir que abarca la integralidad de las personas y considera que la finalidad de la economía es proveer de manera sostenible las bases materiales para el desarrollo personal, social y ambiental del ser humano.

La referencia de la economía solidaria es cada sujeto y las comunidades creadas desde las iniciativas sociales, por lo que no se la identifica según los beneficios materiales de una iniciativa, sino que se define en función de la calidad de vida y el bienestar de sus miembros y de toda la sociedad como sistema global.

La economía solidaria, en el marco de la tradición de la economía social, pretende incorporar a la gestión de la actividad económica, los valores universales que deben regir la sociedad y las relaciones entre toda la ciudadanía: equidad, justicia, fraternidad económica, solidaridad social y democracia directa. Estos valores éticos, sirven de guía a las personas y la construcción de la economía solidaria se fundamenta en seis principios, tal como recoge su carta: en principio de equidad, del trabajo, sostenibilidad ambiental, cooperación, sin ánimo de lucro y compromiso con el entorno.

2 Favreau, L. y Vaillancourt, Y. (2001): «Le modè le québécois d'économie sociale et solidaire», Revue internationale de l'économie sociale, n. ${ }^{\circ} 281.45$. 
Recientemente ha surgido la propuesta de la Economía del Bien Común (2010) comparte con la economía solidaria el objetivo de construir una economía por y para las personas, mediante el bien común. Este concepto no es nuevo, pues aparece explícitamente en toda la teoría aristotélica, y posteriormente en Santo Tomás de Aquino, así como en el ámbito del estudio del comportamiento ético de la empresa (Argandoña, 1998), si bien su plasmación práctica no es fácil de concretar, pues es el bien creado por todos y del que disfrutan todos. Sin embargo, Christian Felber se atreve a dar una definición, entendiendo que el bien común se fundamenta en el respeto y fomento de los valores humanos que compartimos, y que tienen su plasmación en los derechos humanos. Por ello, los valores explícitos que el autor propone son: la dignidad, la solidaridad, el respeto al medioambiente, la justicia social, la democracia y la transparencia.

La Economía del Bien Común, es un sistema que integra propuestas e ideas alternativas al sistema neoliberal dominante, que han sido derivadas de buenas prácticas anteriores o elaboradas por distintos estudiosos. Por hallarse todavía en sus inicios, la EBC se está presentando fundamentalmente como un movimiento empresarial que persigue la reorientación de los objetivos de las empresas; no obstante, es un modelo integrador de diversas propuestas y tiene objetivos en distintos planos de actuación: económico, político y social. Por otro lado, y al igual que plantea la Economía Solidaria, coloca las prácticas de la actividad económica al servicio del hombre y no al revés. Hace hincapié en la incoherencia en la que se ha caído al medir el éxito económico sólo por su valor monetario olvidando medir lo fundamental, que es la satisfacción de las necesidades humanas, cayendo en el error de medir el medio en lugar de la finalidad del sistema económico: su utilidad social.

La EBC presenta en realidad un modelo económico de mercado pero no al estilo tradicional capitalista sino "cooperativo»; se sigue basando en las empresas y la creación de riqueza, por lo que propone que las empresas, además de realizar un balance financiero, realicen un Balance del Bien Común. En la EBC el principal valor es la dignidad humana, sustentada en que todos los seres humanos somos seres con el mismo valor; su contrapartida colectiva se hallaría en el Bien Común, y propone medir su contribución a estos valores si queremos que la actividad económica sea una actividad al servicio del ser humano. (Gómez Calvo, V. 2013). 


\section{La democracia como vía y fin de la economía con valores}

\subsection{La Teoría del Constitucionalismo democrático}

Tanto, para la Economía Solidaria, como para la EBC, cualquier cambio social y económico exige la existencia de una verdadera democracia, y por tanto, una reforma constitucional, en un contexto en el que la mayor parte de las respuestas a la crisis pasan por el desmontaje del Estado Social y la construcción de un nuevo «mini-Estado, sin ninguna reforma política. Este planteamiento se basa en la falta de alternativas viables al sistema capitalista y en el hecho que es necesario sacrificar al Estado Social para que éste perdure. Sin embargo, esta solución nos reconduce a formas de legitimidad de poder ya superadas, como el poder de los mercados, de los poderosos, de los profesionales de la política y en general, de todos aquellos que no están dispuestos a reducir sus privilegios e inmunidad.

Nos enfrentamos a un retroceso en los derechos sociales y el empobrecimiento de nuestras sociedades junto al peligro de un nuevo orden legal, pero ilegítimo, de organización y control social que coarte o elimine las libertades individuales y colectivas. Por todo ello, parece que es el momento de rescatar el constitucionalismo democrático, fundado en la soberanía del pueblo y en el poder constituyente como origen de legitimidad del poder público.

La teoría democrática del poder constituyente nació en el marco de las revoluciones liberales que tuvieron lugar en el último tercio del siglo XVIII. Su función legitimadora, fundamentada en la decisión democrática de la voluntad popular y su capacidad ilimitada de actuación (soberanía) ha constituido un elemento emancipador social a lo largo de la historia. El poder constituyente surge para constituir: instaurar poder constituido sobre las cenizas de lo anteriormente dado bajo la premisa de que lo nuevo constituido también tiene fecha de caducidad y está en manos del poder constituyente. De aquí el carácter revolucionario del poder constituyente, cuya dialéctica funciona como motor del avance social. El Constitucionalismo Democrático fue producto de las revoluciones liberales norteamericana y francesa, cuyo objetivo era activar un poder absoluto con capacidad creadora cuya función fuera instaurar un poder limitado a través de una Constitución.

La Constitución provenía del poder constituyente del pueblo y de la vigencia del principio democrático que la legitimaba y de esta manera, se legitimaba el poder constituido. Ambas naciones rompieron con el Antiguo Régimen, substituyendo la soberanía del Rey por la soberanía 
del pueblo e imponiendo la voluntad general al interés particular de los privilegiados.

Las revoluciones liberales del siglo XVIII sólo aplicaron teorías que se habían ya generado en el pasado reciente o lejano, y reinterpretaron algunas de ellas bajo el prisma de la razón que había despertado durante el humanismo y que cobró forma durante la llustración. El pueblo tiene un poder puro, originario, pero cuyo fruto es un poder controlado, constitucional, una vez es aprobada la Constitución. Ahora bien, la esencia del Poder Constituyente es precisamente que "un pueblo tiene siempre derecho a revisar, reformar y cambiar su Constitución. Una generación no puede imponer sus leyes a las generaciones futuras» (art. 20 de la constitución francesa de 1793, que nunca entró en vigor, aunque fue aprobada).

El pueblo es donde se sustenta toda la potencialidad revolucionaria, el sujeto soberano donde reside el poder constituyente. La asimilación entre pueblo, poder constituyente y soberanía es lo que conforma los cimientos de la Constitución democrática. A su vez, el texto constitucional consagra los elementos de la garantía y desarrollo del gobierno democrático, lo que da paso al Estado constitucional.

Sin embargo, el siglo XIX fue un periodo de adaptación de las Constituciones a los intereses comunes de viejas y nuevas clases sociales, y de rechazo a los principios revolucionarios democráticos. Las Constituciones dejaron de ser consideradas normas jurídicas para pasar, en las monarquías, a obtener la naturaleza de cartas otorgadas y, en las repúblicas, a preconizar el carácter orientativo, no vinculante de su contenido, ya de por sí aminorado en sustancia. Los conceptos de poder constituyente y soberanía incorporaron elementos conservadores que acabaron con su potencialidad revolucionaria y sentido original. Así se delegó la reforma constitucional, que ya no se asentaba en la soberanía popular.

Hoy en día, es necesario hacer frente a los poderes fácticos defensores de intereses contrarios a los generales a través del poder constituyente. Este es propio de una teoría democrática de poder público. El poder constituyente engendra poder constituido y le dota de legitimidad democrática necesaria para su construcción. Se activa cada vez que el poder constituido, como en la actualidad, se deslegitima. Cada generación tiene derecho a cambiar sus normas de convivencia, su Constitución y a decidir sobre su presente y futuro. Negar este derecho sería negar el carácter democrático de dicha sociedad. El siglo XIX fue un periodo oscuro en cuanto a la legitimidad democrática del poder público, lo que se tradujo seguramente en índices de mayor desigualdad social hasta ese momento histórico y que se correspondieron con 
la consiguiente crisis social que enfrentó al Estado liberal a su quebrantamiento, en la forma de comunismos o fascismos. El resultado fue una transformación del Estado liberal que creara unas condiciones materiales de igualdad que lo hicieran viable: Estado de Bienestar o Estado Social. Y ahora que se ha visto amenazado, es incapaz de restablecer los derechos que caracterizaban al constitucionalismo social porque la constitución ya no está formalmente en manos del pueblo, ya que los poderes constituidos se arrogaron la posibilidad del Estado liberal conservador, de cambiarla a su antojo.

La recuperación del concepto democrático de la soberanía, es el fundamento del Estado y el instrumento de la sociedad frente al Estado, el cual lo crea, lo controla y lo coloca a su disposición. El Estado no tiene sentido por sí sólo, sino para mejorar las condiciones de vida de los miembros de la sociedad organizada. La soberanía es el reconocimiento de una poder que la sociedad puede y debe utilizar contra las élites cuando éstas atentan contra el interés general, y la materialización última de la soberanía es el poder constituyente (Aparicio Wilhelmi, M. y otros, 2005).

\subsection{Movimientos sociales, participación ciudadana y empoderamiento político}

En la Economía Solidaria y la Economía del Bien Común, el poder popular no se representa como un «contrapoder» sino como un proceso integral de gestación de nuevos valores y relaciones, ya que la superación del capitalismo requiere de la superación de la lógica del funcionamiento del capital, y esto significa una transformación social de las conciencias. Esta se inicia cuando los pueblos tratan de dar respuesta a sus necesidades y se organizan proponiendo alternativas, impulsando la participación democrática y organizándose políticamente, construyendo así un poder político-cultural desde abajo. Se trata de un proceso integral de transformación consciente y activa del actor colectivo que es protagonista del cambio y que se va gestando así mismo y gestando una nueva realidad en este proceso que abarca a todas las áreas de la vida, pues todas ellas están interrelacionadas (Rauber, I. 2006).

La vía democrática de transformación social implica que en cada momento del proceso haya que optar a favor de quiénes y de qué políticas estamos, y desde dónde, quiénes gobiernas y para qué. Esta debería ser siempre una opción consciente del pueblo, individual y colectiva; y para que así ocurra, debe ser construida, día a día, desde abajo. Para 
ello, la Economía Solidaria y la Economía del Bien Común, proponen la realización de asambleas constituyentes ya que todos los pueblos deberían poder ejercer su derecho a expresas sus puntos de vista e intereses en un proceso permanente. Lo que aparece en la Economía Solidaria y la EBC es una nueva cultura de poder basada tanto en la participación colectiva creciente en el proceso de toma de decisiones como en la ejecución de las resoluciones y el control de los resultados y la gestión gubernamental toda, y para ello es necesario el empoderamiento creciente de los individuos y de los pueblos.

En la actualidad se está llevando a cabo un complejo proceso colectivo, social, cultural, ideológico y político que intenta superar al sistema dominante y sus fallas, si logra tener éxito, se hará sobre la base de una nueva ética y una nueva lógica del funcionamiento social propia de los pueblos que también se construirán desde abajo.

Así la Economía Solidaria y la EBC no sólo abren el camino a la democratización de las actividades económicas sino a una mayor democratización de toda la esfera pública, que es posterior a la democratización económica. La participación democrática implica que los afectados por las decisiones tomadas en materia económica tengan voz en esta toma de decisiones, y aunque no es garantía contra los errores, la detección de estos constituye parte del proceso y es más fácil corregirlos, puesto que las decisiones no son nunca definitivas y siempre es posible encontrar nuevas soluciones.

La política de dejar hacer al libre mercado no puede dar solución a problemas sociales como la pobreza, las desigualdades, la emigración, carencia de infraestructuras, etc. porque estos problemas hunden sus raíces en las relaciones institucionales de poder en los contextos sociales donde se producen, y por lo tanto, sólo pueden ser resueltos incrementando la participación democrática de la ciudadanía para equilibrar las relaciones de poder. No sólo eso, si recuperamos la noción de constitucionalismo democrático, fundado sobre la soberanía del pueblo y en el poder constituyente como origen de legitimidad de todo poder público, el pueblo tiene un poder puro, originario, que se activa cada vez que el poder constituido se deslegitima al no representar los intereses generales de la sociedad. Cada generación tiene derecho a cambiar sus normas de convivencia y su constitución y negar este principio sería negar el carácter democrático de la sociedad misma.

Como ya comentamos anteriormente en este artículo, en el siglo XIX, las constituciones perdieron su carácter "revolucionario» al adaptarse a los intereses de las clases sociales dominante, pasando de ser consideradas normas jurídicas en las monarquías, a obtener la na- 
turaleza de cartas otorgadas, y en las repúblicas, a preconizar el carácter orientativo-no vinculante de su contenido. De esta manera, los conceptos de poder constituyente y soberanía incorporaron elementos conservadores que acabaron con su potencialidad revolucionaria y sentido original (Aparicio Whilhelmi, y otros, 2012). De hecho, las constituciones actuales no están formalmente en manos del pueblo, ya que los poderes constituidos (políticos), se arrogaron el poder de cambiarla. Por ejemplo, la constitución española de 1978 pone muchos cortapisas a la soberanía popular en el Título X: como los límites a la iniciativa popular (áreas como la laboral y la económica quedan fuera del alcance de las iniciativas legislativas populares), condiciones específicas para las convocatorias de referéndums consultivos, etc. todo ello dispuesto para que el poder constituyente del pueblo no se active.

Sin embargo, la Teoría del Poder Constituyente nos lleva a la regeneración de lo que existe, lo ya constituido, a través de la decisión democrática del pueblo. La recuperación de un concepto democrático de la soberanía no es sólo el fundamento del Estado sino el instrumento que la sociedad utiliza frente a al Estado para crearlo, controlarlo y colocarlo a su disposición. El Estado sólo tiene sentido como instrumento para mejorar las condiciones de vida de los miembros de la sociedad. La soberanía es el reconocimiento de un poder que corresponde sólo al pueblo soberano y que la sociedad debe utilizar contra las élites cuando éstas atentan contra el Bien Común y la materialización de dicho poder constituyente.

\section{El proceso de transformación de la EBC: la construcción de una democracia económica, social y política}

La clave innovadora de la EBC es proponer un sistema económico que fomente los comportamientos basados en los valores humanos, frente a aquellos que los ignoran, mediante un cambio en el diseño de las instituciones económicas. El sistema capitalista cuenta con un marco jurídico y de incentivos que premia el egoísmo y la competencia, y como hemos comprobado en epígrafes anteriores los resultados obtenidos distan mucho de ser el bien común.

Si deseamos una economía basada en valores humanos, lo lógico es diseñar un sistema económico que premie a las empresas que generan bien común y no los comportamientos que lo reducen, tal como ocurre con el actual sistema. El modelo propuesto se denomina economía de mercado cooperativo porque se fundamenta en la propiedad privada, con límites, la actividad empresarial y la creación de riqueza, 
pero no sólo económica ni a cualquier precio, y donde se incentiva la cooperación y la creación de bien común.

De hecho, la reflexión inicial de la que parte la EBC es que las relaciones sociales se fundamentan en valores como: la honestidad, la dignidad, la cooperación, la solidaridad, la felicidad, la compasión, el altruismo, la amistad, etc. Sin embargo, la economía capitalista está regida por los principios del egoísmo, la competencia y la maximización del beneficio, que ha demostrado estar muy lejos de conseguir la calidad de vida para todos los ciudadanos. Esta contradicción se produce porque el sistema económico actual está diseñado para premiar e incentivar esos comportamientos. En ambas tipos de mercado, la empresa necesita cubrir sus costes, por tanto un balance financiero saneado es necesario, ahora bien en el mercado capitalista si una empresa desea pagar bien a sus trabajadores, a sus proveedores, etc incurrirá en una serie de costes que pueden hacer peligrar su situación financiera, mientras que una empresa que no lleve a cabo estas buenas prácticas tendrá más posibilidades de no cerrar. Ante esta contradicción, la EBC propone un sistema que premie a las empresas que fomenten el bien común, puesto que la sociedad se está beneficiando directamente de este comportamiento. De esta forma, los incentivos de las empresas y los de la sociedad siguen los mismos parámetros y no entran en conflicto.

El elemento clave en esta propuesta es la importancia de la cooperación como motor del progreso de la sociedad, pues gracias a ella, todos ganan, como sustituto de la competencia, donde algunos (o muchos) tienen que perder. De hecho, la teoría clásica ve en la división del trabajo, que exige cooperación dentro de la empresa, como medio del crecimiento de la producción, y defienda las ventajas de la competencia perfecta gracias a que favorece los procesos de imitación de las prácticas exitosas, cuando realmente esta información no se comparte y es muy difícil de conseguir en un contexto de competencia. Por el contrario, la cooperación directamente permite y premia estos procesos de mejora compartida, dentro de la empresa y entre éstas, por tanto, una forma de fomentarla es la recompensa directa por medio de incentivos públicos. Ahora bien, la EBC no solo crea un sistema de premios para las empresas que cooperen con trabajadores, proveedores, y otras empresas, sino con la sociedad en general, además de ofrecer toda una serie de propuestas de reformas económicas y políticas que iremos desgranando.

Su primera aportación es una propuesta para medir el bien común, pues en palabras del premio Nobel Joseph Stiglitz «Lo que medimos afecta lo que hacemos, si no medimos lo correcto, no haremos 
lo correcto». Esta medición del éxito se realiza a nivel microeconómico mediante el balance del bien común, y a nivel macroeconómico, mediante la evaluación de producto del bien común. La propuesta que está más avanzada es la medición a nivel microeconómico explícita del bien común generado por una empresa, mediante una herramienta denominada «matriz del bien común», cuyos criterios se establecieron a partir del acuerdo de un conjunto de empresarios en Austria, y que es un proceso en construcción, pues de hecho está en su versión 4.0. Los indicadores propuestos miden el efecto de las actuaciones de la empresa sobre los valores de la dignidad humana, solidaridad, sostenibilidad ecológica, justicia social, participación democrática y transparencia, en función de los grupos de personas afectadas: proveedores, financiadores, empleados/propietarios, clientes / productos / servicios / co-empresas, y ámbito social: región, generaciones futuras, personas y naturaleza. En las intersecciones de estos dos criterios, valores y grupos afectados, aparecen criterios para evaluar aspectos como las condiciones laborales, el reparto de la renta y del trabajo,etc. Este proceso evaluativo se concreta en un valor numérico, que es el balance del bien común, y que ofrece una cuantificación del aporte de la empresa al bien común. Es importante destacar que el valor primordial de la EBC y de la economía solidaria es la democracia, y esta tiene su mayor desarrollo en las formas organizativas donde una persona es un voto. No obstante, la evaluación que propone la EBC facilita que la empresa tome conciencia del grado de generación de bien común, lo que permite graduar el grado de compromiso alcanzado con el proceso de transformación, sin que el cumplimiento de los principios democráticas estén totalmente presentes, frente a la economía solidaria, que sólo considera que las empresas que están bajo este paradigma son las formas asociativas de la economía social.

Desde un punto de vista práctico, Christian Felber propone, en una primera etapa, que las empresas, municipios y organizaciones se comprometan a medir su aporte al bien común. En una segunda etapa, la EBC prevé que las empresas/organizaciones que ya hayan medido su participación al bien común mediante el balance, hagan pública su puntuación mediante su publicación en los medios de comunicación, en la página web de la EBC y otras fórmulas que se están barajando. Además, las empresas etiquetarán sus productos con un distintivo o color en función de la puntuación obtenida, de esta manera los consumidores serán conocedores en su toma de decisiones de cómo la empresa favorece al bien común. Así, el consumidor tiene la información que necesita y puede ejercer su derecho de participación y su responsabilidad individual y colectiva en las compras que realiza. 
En la actualidad, existen muchos certificados y evaluaciones sobre el comportamiento ético de las empresas: la propuesta de la EBC, la auditoria social de la economía solidaria, las memorias de responsabilidad social, GRI; norma 26.000, SA8000, SG21, EFR o RS10, entre otros. Sin embargo, la gran diferencia está en el hincapié que hace la EBC en la transformación del marco institucional, que propone en la tercera fase. Es fundamental entender que el sector público ofrece un marco jurídico al mercado capitalista que permite la maximización de beneficios, preservando el derecho de la propiedad sin ningún tipo de restricción, donde sobrevivir implica competir y dañar a otros. Posteriormente, la actividad del sector público intenta solucionar, en el mejor de los casos, los «fallos del mercado»: pobreza, desigualdad, deterioro medioambiental,.. y surge así en el siglo xx conocido «Estado de bienestar», como ya hemos comentado. De igual forma, el sector público, puede también diseñar un marco legal del mercado, pero en este caso, cooperativo, pues la EBC, como cualquier sistema económico necesita de unas «reglas de juego». En la EBC no hay más regulación de la que pueda existir hoy en día, pero su objetivo no es «enmendar»los resultados del mercado, sino corregir los mecanismos e incentivos para generar otros resultados desde el propio mercado, pero en consonancia con valores humanos, de forma que el sistema premie la generación del bien común y no la maximización de los beneficios a toda costa.

Pues bien, la EBC plantea un sistema de certificación del balance basado inicialmente en auditoría, para que en el futuro cuente con la inspección pública de dicho certificado, al igual que ocurre en actualidad con la declaración de impuestos, que son controlados mediante las inspecciones públicas. El BBC será obligatorio para todas las empresas y estará auditada externamente, será difundida públicamente y permitirá al consumidor conocer en qué medida la empresa cuyo producto o servicio adquiere, contribuye al bien común. Además, como El BBC de una empresa se verá afectado por el BBC de sus proveedores, instituciones crediticias y empresas con las que colabora; ésta tenderá a colaborar con empresas con un elevado BBC.

Además el balance del bien común, es la herramienta de constatación que empleará el sector público para la aplicación de los incentivos a las empresas «productivas del bien común», en concreto se propone: disminución de impuestos, créditos bancarios en condiciones más favorables, preferencia en la contratación pública, cooperación con universidades públicas en investigación y ayudas directas. Esto implica que la empresa que fomente el bien común podrá ofrecer los productos a precios más reducidos que aquellas que crean mal común, por lo que les resultará es más difícil sobrevivir en el largo plazo. 
Además, la EBC, propone también una serie de reformas que tienen como objetivo conseguir que la economía esté al servicio de las personas y no al revés, que se pueden resumir en tres grandes propuestas. La primera es limitar a acumulación de capital con el objetivo de convertir el beneficio en un medio para generar más bien común y no un fin. La segunda, al igual que la economía solidaria, es que el trabajo es la forma natural de desarrollo personal y el medio para conseguir los recursos necesarios para vivir, por ello el sistema debe favorecer la incorporación de las personas a las diferentes formas de trabajo y que éste permita una vida digna, con la propuesta de un establecimiento de salarios máximos y el derecho de propiedad limitado y la tercera es la importancia de los bienes democráticos, aspectos que desarrollamos a continuación.

La limitación de la acumulación de beneficios, más allá de unos límites, elimina el incentivo al crecimiento pues ni genera más beneficios ni tampoco una ventaja adicional para la empresa porque no puede crear barreras de entrada en el mercado, rompiendo así la causa fundamental de la aparición de la desigualdad económica y política, y de incentivos a la no cooperación empresarial.

Ello no implica que el beneficio monetario desaparezca, si no que deja de ser un fin en sí mismo, y se convierte en el instrumento para fomentar lo que verdaderamente importa a las personas, el bien común, mediante una serie de usos permitidos y prohibidos. Así, entre los usos permitidos estarían las inversiones cuya viabilidad sea financiera y social porque generan bien común, por lo que el plan de negocio tendrá una apariencia totalmente diferente a la actual; las provisiones para pérdidas: que deben ser depositadas en la banca orientada al bien común; el aumento del capital propio, y que pueden servir en el futuro como complemento de las pensiones públicas; el reparto entre los colaboradores de la empresa, estando limitado a un número de veces el salario mínimo y los préstamos a clientes, empresas o proveedores, pero sin intereses. Por otro lado, los usos no permitidos de los beneficios serían: el reparto de beneficios entre propietarios que no trabajan en la empresa, la adquisición y fusión de empresas sin su consentimiento, las inversiones financieras, pues el efectivo en la economía del bien común no es sólo un bien privado, sino público, por lo que si se tiene liquidez se puede poner a disposición de la banca, y por último, las donaciones a partidos políticos.

Pero las empresas también pueden quebrar porque estarán en una economía de mercado, aunque previamente las empresas deben cooperar entre ellas para buscar soluciones: disminuir horarios laborales, crear nuevas especialidades, organizar cursos de formación, buscar 
puestos de trabajo alternativos, fusionar voluntariamente dos negocios, etc. Además, las grandes empresas, con más de 250 trabajadores, deben ser propiedad de sus empleados y de los ciudadanos, que estarán representados por delegados elegidos directamente en parlamentos económicos regionales, y no por políticos.

El capital no se remunerará, no habrá dividendos ni pago de intereses. Si la empresa necesita capital puede conseguirlo de los bancos orientados al bien común (que no distribuyen dividendos ni pagan intereses por los ahorros); de particulares que se involucren en la empresa; de jóvenes que aporten su dote democrática; o de préstamos sin coste de otras empresas, etc. La inexistencia de retribución del capital puede plantear la duda de si paralizará la inversión, pues el riesgo de quiebra existe. Ante esa crítica debemos reflexionar sobre la idea que la empresa es una acción colectiva en la que no sólo arriesga quien pone el capital, sino también el trabajador que contribuye con su trabajo y asume el riesgo de perder su sustento vital. Por eso el «inversionista» sólo participa en los beneficios si trabaja en la empresa, y su retribución puede ser más alta, pero siempre dentro de los límites legales establecidos.

Los mercados financieros han demostrado que no sirven para la finalidad que estaban pensados: canalizar el capital en actividades que lo necesitasen. Por ello, la EBC propone el cierre de los mercados financieros. Las personas viven de su trabajo, y sus ahorros estarán garantizados mediante la banca democrática, bancos cooperativos o cajas de ahorro, que sólo negociarán con depósitos y créditos para la economía real. Los intereses, que se denominan «tasas crediticias», se cobran por los préstamos y tienen como finalidad sufragar los gastos, como cualquier otra actividad empresarial. La sociedad anónima no se proveerá de fondos privados, sino de participaciones de ciudadanos a nivel regional (energía) o internacional (software). Asimismo, la deuda pública debe contar con límites legales, y el banco central es el encargo de prestar dinero al sector público.

La segunda propuesta de la EBC es el cambio de papel del empleo para el empleador y para las personas empleadas. Por un lado, todas las personas por el hecho de serlo, tienen derecho a una renta básica que garantice una vida digna, lo que permite romper la dependencia de la venta del tiempo a cualquier precio. Así ocurre actualmente, pues como muestra Eurostat, el $14 \%$ de la población que trabajaba en España a tiempo completo en el 2008 estaba por debajo del umbral de la pobreza. Por otro, el sistema pretende crear mecanismos para que el empleo sea accesible a todas las personas que puedan trabajar, por tanto no es sistema que da, sino un sistema que crea medios para que 
todos puedan aportar su esfuerzo, y lógicamente disfrutar de él mediante unos ingresos dignos, sin que nadie se apropie del trabajo de otros.

En el caso de que hubiese desempleo, se minimiza porque las empresas son recompensadas por contratar a más gente y por buscar fórmulas cooperativas para solucionar los problemas de otras empresas. Por otro lado, la reducción de la jornada permitiría el reparto del empleo y dejarían tiempo para otras actividades que completan a las personas: trabajo propio, trabajo comunitario y el cuidado de las relaciones en el trabajo. Asimismo, la EBC propone un año sabático opcional cubierto con la renta básica, que también facilitaría el aumento del empleo.

En cuanto a la retribución del trabajo, la EBC propone la existencia de un salario mínimo y máximo para cada hora de trabajo, con una diferencia entre el máximo y el mínimo de 10 o 20 veces (o importe que decida la soberanía democrática). Esta propuesta contrasta con la situación en EEUU donde el directivo mejor pagado gana 350.000 veces lo estipulado en el salario mínimo interprofesional. La EBC no sólo limita la renta mínima y máxima sino también la propiedad privada, que no podrá exceder de 10 millones de euros; y el derecho hereditario, que no podrá exceder de medio millón de euros por persona y en el caso de empresas familiares a diez millones de euros por persona. Las herencias que excedan esos límites se distribuirán como "dote democrática» a personas de la generación siguiente, pues cuanto más justamente se distribuya el capital inicial mayor será la igualdad de oportunidades.

Por último, es fundamental destacar un aspecto fundamental como es la gestión de los bienes comunes democráticos, como una esfera de la propiedad diferente a lo estrictamente privado o público, donde la ciudadanía tiene la posibilidad de ejercer mecanismos de colaboración y participación diferentes a la esfera del sector público, y que implica la creación de redes sociales basadas en la confianza en la gestión de las empresas de suministros de energía, escuelas, redes ferroviarias, servicios de correos o bancos que ofrecen bienes públicos, así como toda una serie de bienes comunales cuya gestión es realizada por la población y no por el sector público.

Todos estos procesos de cambios no se pueden producir sin una verdadera democracia, donde la transformación comience en las personas y desde los movimientos sociales desde el ámbito local a otras esferas territoriales, como comentábamos anteriormente.

El proyecto de cambio de la sociedad desde abajo tiene su marco inicial de actuación en el contexto local. Esto supone en primer lugar, un cambio en los objetivos del desarrollo local desde la competitividad 
a la generación de bien común, por lo que todos los agentes deben compartir ese objetivo, mediante un cambio de valores y de incentivos. El detonante natural es la demanda de los ciudadanos de otra forma de hacer política y economía, y esto es más factible en el ámbito de local, donde la democracia participativa es más fácil de ejercitar por las personas. De igual forma, la empresa local puede encontrar una vía natural de cooperación y colaboración con otras empresas locales. Por su parte, las administraciones locales, a pesar de tener competencias limitadas, pueden conocer mejor la realidad del territorio y ejercer de facilitadoras e impulsoras de la creación de redes. Además, pueden ser generadoras de bien común en su gestión interna, en su relación con los proveedores, y con los ciudadanos, como ejemplo del cambio de valores.

\section{Conclusión}

Como hemos visto hasta ahora, vivimos en sociedades donde la democracia se haya secuestrada por los poderes fácticos, son democracias formales pero no reales. Sin embargo, no todo está perdido, corresponde a los ciudadanos el despertar a la realidad, el empoderarse y ayudar a empoderar a otros para que la sociedad en su conjunto tome conciencia de que en una auténtica democracia, el pueblo es soberano, y es sobre él sobre quien recae el poder constituyente, el poder de crear.

En este nuevo despertar que está aconteciendo a lo ancho y alto del globo, de millones de personas que se organizan en grupos y movimientos para provocar el cambio y transformar la realidad, todavía debemos ir un pequeño paso más allá, aunque de inmensa profundidad y transcendencia, porque significa una ampliación de nuestra consciencia: cada uno de nosotros ostenta un gran poder, aunque no seamos conscientes de ello. Por separado, aislados como individuos, somos pequeños en comparación con el poder de un gobierno, de un ejército o de una multinacional, pero juntos, somos el $99 \%$ de la población que sigue los dictados de sólo un $1 \%$ que ostenta el $43 \%$ de la riqueza mundial y que por tanto, domina en gran medida el curso de nuestro destino. No obstante, nosotros somos la inmensa mayoría y donde debe recaer la legitimidad de cualquier propuesta que queramos que sea pública y legal y de donde debe partir la construcción de cualquier alternativa.

En la actualidad, la legalidad no es lo mismo que la legitimidad, mucho de lo que ocurre a diario a nivel social, político y económico es 
legal pero profundamente ilegítimo porque afecta negativamente a la mayoría de la población. De nosotros mismos depende que toleremos situaciones de injusticia o que despertemos a la realidad y decidamos movilizarnos y cambiar el rumbo de los acontecimientos adoptando otros valores y construyendo y poniendo en marcha alternativas legítimas en pos del Bien Común.

El primer paso es el cambio de valores, y el segundo el cambio de las instituciones, y precisamente, la gran aportación de la EBC es crear un sistema que fomenta y reconduce el comportamiento de los actores económicos, es decir de las personas, con los valores humanos básicos.

\section{Bibliografía}

Aparicio Wilhelmi, M. y otros: Por una Asamblea Constituyente. Una solución democrática a la crisis, Ediciones Sequitur, Madrid, 2005 disponible en: http://www.rebelion.org/docs/147698.pdf

ARGANDONA A. "The stakeholder theory and the common good». Journal of Business Ethics 17, 1998,1.093-1.102.

Conil SANCHo, J.: Horizontes de economía ética, Editorial Tecnos, Madrid, 2004.

CORTINA, A.: ¿Para qué sirve realmente la ética?, Paidós, Barcelona, 2013.

Esparta SoloetA, I.: «Análisis Económico Institucionalista: Una economía política para la transformación social», Escuela Universitaria de Estudios Empresariales de Bilbao, UPV, 2002, disponible en http://pendientedemigracion.ucm.es/info/ec/jec8/Datos/documentos/comunicaciones/Fundamentos/ Esparta\%20I\%F1aki.PDF

FAVREAU, L. y VAILLANCOURT,Y. (2001): «Le modè le québécois d'économie sociale et solidaire», Revue internationale de l'économie sociale, n. ${ }^{\circ} 281$, 45-67.

Divar Garteiz-Aurrecoa, J. «Filosofía de la cooperación», Revista Deusto de Estudios Cooperativos, n. ${ }^{\circ} 1$, septiembre, 2012, pp. 33-53.

Felber, C.: Neue Werte Für die Wirtschaft. Eine Alternative zu Kommunismus und Kapitalismus, Ed. Deuticke, Viena, 2008.

Felber, C.: La economía del bien común, Grupo Planeta, Ediciones Deusto, Barcelona, 2012.

GANGOPHADY, P.: Economics of rivalry, conflict and cooperation, Hackensack, N.J. : World Scientific, 2011.

GeORGE, S. et al.: ¿Hacia dónde va el mundo? 2012-2020: la última oportunidad, Icaria, 2012.

Gómez Calvo, V.: «Acercamiento a las prácticas de la Economía Solidaria, la Economía Social y la Economía del Bien Común, ¿qué nos ofrecen?», para ser publicado en la Revista Barataria, número 15, 2013, http://silente.es/ wordpress/?p=526 
Gómez Calvo, V. y Gómez Álvarez, C.H.: «Fundamentos y relaciones entre el Desarrollo Humano, la Economía del Bien común, la Economía Solidaria y la Economía Social», Comunicación para el VII Coloquio Ibérico Internacional de Cooperativismo y Economía Social. Sevilla, 19 y 20 de septiembre de 2013.

KEYNES, M. (1923): «Breve tratado sobre la reforma monetaria», Fondo de Cultura Económica, Méjico, 2004.

Latouche, S.: Pequeño Tratado del Decrecimiento Sereno, Icaria, Barcelona, 2009.

lópez Castellano, F. "Una sociedad "de cambio y no de beneficencia". El asociacionismo en la España Liberal (1808-1936)», CIRIEC-España, n. ${ }^{\circ} 44$, 2003, pp. 199-228.

MACEWAN, A.: ¿Neoliberalismo o Democracia? Estrategias y alternativas económicas para el siglo XIX, Ediciones Octaedro, Intermón Oxfam, Barcelona, 2001.

MCLEOD, M. (coord.): Política con conciencia, Kairós, Barcelona, 2010.

MONZÓN, J.L. y ChAVES, R.: La economía social en la Unión Europea, Comité Económico y Social Europeo, 2011.

RAUBeR, I.: "Sujetos políticos. Rumbos estratégicos y tareas actuales de los movimientos sociales y políticos». Sango Domingo, República Dominicana, Editorial Pasado y Presente XXI, 2006, disponible en http://es.scribd.com doc/77913529/Isabel-Rauber-Sujetos-Politicos

RAzETO, L.: Economía de solidaridad y mercado democrático, Ediciones PET, Santiago, 1984.

Rosen, F.: «El viaje de John Stuart Mill hacia el socialismo», Revista Iberoamericana de Estudios Utilitaristas, XVIII/1-2,2011, 23-43.

SAMPEDRO, J.L.: El mercado y la globalización, Ediciones Destino, Madrid, 2002.

SMITH, A. (1776): Una investigación sobre la naturaleza y causas de la riqueza de las naciones, Madrid, Tecnos, 2009.

StIGLITZ, J.E.: El malestar en la globalización, Taurus, 2002.

Stiglitz, J.E.; Sen, A.; FitoussI, J.P.: Medir nuestras vidas, RBA Libros, 2013.

VILLASANTE, T.R.: Las democracias participativas, HOAC, Madrid, 1995. 